To appear in the European Journal of Engineering Education

Vol. 00, No. 00, Month 20XX, 1-22

\title{
A Survey of Good Practice in Control Education
}

\author{
J.A.Rossiter $^{a *}$, B.Pasik-Duncan ${ }^{b}$, Sebastian Dormido ${ }^{c}$, Ljubo Vlacic $^{d}$, Bryn Jones ${ }^{a}$ and \\ Richard Murray ${ }^{e}$ \\ ${ }^{a}$ Dept. ACSE, University of Sheffield, UK. Email: \\ j.a.rossiter@sheffield.ac.uk,b.l.jones@sheffield.ac.uk, ${ }^{b}$ Department of Mathematics, University of \\ Kansas, USA, Email:bozenna@ku.edu, ${ }^{c}$ Escuela Tecnica Superior de Ingeniera Informatica, \\ UNED, Madrid, Spain. Email: sdormido@dia.uned.es, ${ }^{d}$ School of Engineering, Griffiths \\ University, Melbourne, Australia, ${ }^{e}$ Control $\&$ Dynamical Systems and Bioengineering, Caltech, \\ USA.Email: murray@cds.caltech.edu
}

(Received 00 Month 20XX; final version received 00 Month 20XX)

\begin{abstract}
This paper gives a focussed summary of good practice taken primarily from engineers who are responsible for teaching topics related to systems and control. This engineering specialisation allows the paper to give some degree of focus in the discussions around laboratories, software and assessment, although naturally many of the conclusions are generic. A key intention is to provide a summary document or survey paper which can be used by academics as a start point in studies of what is effective in the discipline. It is also hoped that such a summary will will be useful to engineering institutions in drawing together and disseminating open access resources that are freely available to the community at large.
\end{abstract}

Keywords: Control education, remote and virtual laboratories, laboratory assessment, open access resources.

\section{Introduction}

Control systems technology continues to change rapidly, causing a need to continually revise the way we educate students. Moreover, alongside technological advances, there has been an increasing awareness of what constitutes an effective learning environment and the general perception is that this is vastly different from traditional models. A recognition of the importance of education is evidenced by the existence of educational committees within many engineering institutions, including IEEE. This article focuses on the work of several control system educators who, under the umbrella of their affiliations with IFAC (International Federation of Automatic Control), AACC (American Automatic Control Council), and IEEE, have shared their ideas on, and experience from, advancing the practice of control systems teaching and learning.

The community benefits from a consolidation of good practice in control engineering resources in general, with education being an essential component of that. Indeed, a preliminary website devoted to control resources was authorized and created by IFAC in 2008 (Perez, Dormido and Vlacic 2011) and updated recently (IFAC 2016). The IFAC educational committees felt that a publication summarizing good practice and opportunities within control education would be useful to the community. A short summary

\footnotetext{
${ }^{*}$ Corresponding author.
} 
was presented at the IFAC world congress in 2014 (Rossiter, Dormido, Vlacic, Jones and Murray 2014) and this constitutes the longer and more complete version of that work.

This article is intended to be useful primarily to those involved in delivering education, who may wish to update or improve their current practices, but it will also be of interest to many others who may benefit from an awareness of how first degrees are delivered. A wide range of scenarios and concepts will be covered, with an underlying focus on the following questions:

(1) What is accepted good practice?

(2) What is the evidence and context?

(3) How and why should I try this?

\subsection{Historical Context and Future Opportunities}

In the past, there were relatively limited opportunities and mechanisms for educational delivery and assessment. Recently, there has been significant pressure to understand the learning process, apply research to it, and exploit advances in technology. Consequently, there have been substantial advances in the learning environment and the awareness of academic staff of how to support student learning. It is now commonplace for new academics to achieve formal qualification in learning and teaching (in the UK, for example, this is ratified by the higher education academy www.heacademy.ac.uk). This encourages staff to reflect in detail on learning outcomes, by considering questions such as: (i) what do I want the students to be able to do, and why? (ii) how can I be sure they achieve this? (iii) what effective good practice is there? Staff have both incentive and support to pursue good practice. One core example of the increased focus on pedagogy is the discussions on the role of a conventional didactic lecture (Crouch and Mazur 2001; Lancaster and Read 2013); traditional modes of delivery still have a role, but a reduced one.

In parallel with pressures for academics to become 'professional' educators, as well as researchers, there have been significant changes in the Learning \& Teaching technology domain. Leaving aside smaller issues such as the ease with which staff can now replicate notes for distribution, the power of computing has had the most impact. Since the desktop computer became affordable around the early 1990s, there has been the potential for universities to allow a massive increase in student access to computing. One simple benefit is the opportunity to include more complex and interesting problems on written exams, by allowing access to suitable software during assessment to aid with tedious number crunching. There is evidence that the community at large is now beginning to realize this on a broader scale and thus the integration of software packages into assessments and even formal examinations is becoming the norm as opposed to a rarity (Lynch and Becerra 2011; Rossiter, Giarouris, Mitchell and Mckenna 2008).

Similar opportunities exist with regards to laboratory access. While time spent sitting in front of equipment will always be limited at most universities due to a combination of financial, space, and timetable restrictions, there is now the potential to allow remote access to 'laboratory-like' activities 24/7. Indeed, the increasing power and speed of the Internet allows for real-time access to data, laboratories (Gustavsson 2009), and related resources. Software has also improved so that the average academic can author relatively advanced simulators (Cameron 2009; Guzmand 2006; Khan and Vlacic 2006; Goodwin 2010) quickly and without need of coding expertise. This has led to many innovations such as remote access laboratories, virtual laboratories, interactive online laboratories, computer-aided assessment, online audio, video, and text files, and so forth (de Jong, Linn and Zacharia 2013; Mathtutor 2012; Rossiter 2016; Murray 2013). Despite the wealth of available suggestions in the literature about the implementation of all this new technology, many institutions have yet to really avail themselves of it. 
The rapid advances in computing technology also mean that departments now have the potential to develop very cheap equipment (Hill 2015; Reck and Sreenivas 2015; Egerstedt 2014). No longer does each experiment need an expensive IO card or similar; instead one can plug into the computer directly via a USB port. This allows for the production and distribution of multiple copies of real equipment, which can even be taken home by students (Taylor, Jones and Eastwood 2013; Eichlere 2013).

This article also has a brief section that aims to recognize the increasingly multidisciplinary skill requirements for modern engineers. In the same vein, systems and control skills are required in many disciplines outside of engineering. Hence, there are opportunities for engineers to recognize how their skill sets can be more broadly applied and, conversely, opportunities to introduce novel 'systems' modules into other areas (Murray 2013).

\subsection{Summary of Contribution}

This article summarizes best practice in tertiary education with a specific focus on the delivery of systems and control topics. The first section is generic (that is, applicable to all disciplines), but the authors feel it will be useful to readers who may not come across such concepts otherwise. It focuses briefly on the largest student-staff interaction, which is through the lecture (Crouch and Mazur 2001); this is where we have the most time and opportunity to influence students. It also covers online learning tools and the use of software in assessment. Some examples from within control teaching are given. The next section considers student engagement and the use of technology in helping students learn better, within a systems and control scenario. The following two sections focus on laboratories and equipment to support the learning of systems and control and, in particular, how modern technology provides opportunities for cheaper and more accessible activities. There is a dedicated discussion of 'take-home-laboratories;' that is, hardware students can have access to $24 / 7$. The final section touches on the evangelization of systems and control to disciplines outside of engineering.

This article will not discuss issues linked to accreditation (UK-SPEC 2016; ABET 2016(@; ENAEE 2016), industrial involvement and overall curriculum design/holistic student development.

\section{The Design and Supply of Staff Involvement in Module Teaching}

This section focuses on generic principles related to education, beginning with what constitutes an effective lecture, particularly in the context of something like control. A critical point is that diversity is usually good and thus lecturers are encouraged not to adopt a single technique; often, a variety of approaches within the same course is best. There is also a brief discussion of virtual learning environments (VLE), the opportunities these offer to improve the student learning experience, and the use of software in assessment.

\subsection{Didactic Lectures}

Employers are interested in students' ability to abstract, see the big picture, analyze real world problems, learn independently, account for issues such as risk and reliability, etc. (Panel 2013). A poorly delivered didactic lecture can, conversely, give the impression that the lecture content is the totality of what students need to know and thereby encourage a memorize-and-regurgitate approach to learning (Rossiter and Gray 2010). In a similar 
vein, poorly designed tutorial questions may not test problem solving but rather students' ability to replicate/copy from notes (Kawski 2013).

In a feedback loop, a core component is the control law; ultimately, it is this that governs system behavior and not the measurement/information. Within a learning scenario, the lecturer provides the information or measurement but it is the student who acts as the control law. Thus, effective learning can only take place when the student is active! A passive student is effectively open-loop and may learn very little. It is recognized that student engagement drops rapidly after 15 minutes (Huxham 2005) of didactic presentation. Hence, the overall portfolio of lectures must not be overloaded with didactic presentation techniques that convince students, by example, that passivity and replication is what is valued. For those who are interested, there is a chapter in (Abdulwahed 2010) on links between learning and feedback loops.

Despite these concerns, didactic presentation modes still play an important role and should not be removed entirely. After all, an effective feedback loop does benefit from good quality measurement/information. Important considerations in the delivery of didactic lectures include the following.

(1) Many students do not parse formulae correctly; what they 'say' does not match what they write. Watching a lecturer carefully write/talk through a solution on a blackboard with the correct language will help them learn the correct associations and approaches.

(2) A screen dump of a solution consisting of several steps can confuse or switch students off. By writing a solution out during the lecture, an instructor is forced to go at a pace where students can clearly identify the steps and thinking and thus follow the argument. This helps students become active and not passive!

(3) There are some important messages that the lecturer wants to be sure are presented correctly; ensure no measurement error!

(4) Good practice suggests lecturers should face students and thus use an overhead projector, pen-enabled laptop (Wilson and Maclaren 2013), or smart screen. Again, this encourages engagement and reduces passivity.

\subsection{Online Lectures or No Lectures and Sharing Learning Resources}

One of the most obvious weaknesses of lecture deliveries is that they happen once, at a fixed time, and if you miss them there are no second chances. Even for those present, a temporary lapse in concentration can mean the failure to note an important point. Moreover, difficulty picking up the nuances of the lecturer's speech can result in a misunderstanding or gap in the notes. These problems are known to be amplified in the case of international students (Rossiter 2009) who are less fluent in the language of instruction. In such cases, there is substantial evidence that the recording of lectures is hugely valuable (Fidler, Middelton and Nortcliffe 2006; Middleton 2013) as students can listen to the lecture again later and correct any initial misunderstandings, reinforce the sounds and interpretations of keywords, update and correct their notes, and so on. This also helps those who have no language difficulties.

Staff may begin to wonder whether recording lectures eliminates the need for a face-toface lecture altogether. There is evidence (Parson 2009) that lecture recording does not, in fact, reduce class attendance and indeed this matches the authors' personal experiences. Recordings are best used as a complement to, rather than a replacement of, in-person attendance of lectures. Nevertheless, there remains a question about the precise role of recordings within an overall curriculum delivery and this is of direct interest to the control community. To what extent would a validated repository of learning resources in systems and control be useful to both academic staff and students (Saunders and 
Hutt 2012; Willaims and Fardon 2005)? One example of a very successful project, which developed a freely available set of online lectures on core topics for first year engineers, is within the mathematics community in the UK and now the EU (Mathtutor 2012). A similar site covering other topics is available at (Khan Academy 2016). The University of Sheffield also has an internationally popular site (Rossiter 2013) on control topics and many others, such as (Egerstedt 2016), have developed equivalent open access resources. It is encouraging to note that IFAC is moving towards the creation and management of resources in control engineering (IFAC 2016) and colleagues are encouraged to submit their links to this site for review.

Open access resources give students the freedom to study in their own time and thus to acquire key skills. Moreover, the availability of didactic resources online removes the pressure on the lecturer to cover everything in lecture time, instead leaving more time and freedom to use some lecture time for more engaging activities (Crouch and Mazur 2001; Lancaster and Read 2013). There is growing evidence that, given suitable online/preparatory resources, lectures can be replaced by workshop type sessions in open classrooms (Gould 2013; TEAL 2016) where students work on problem solving in small groups. Such sessions ensure students are active in the learning process and thus they learn much more than they would by just listening to a lecturer. Student evaluations indicate the lecture flipping approach is popular and effective (Rossiter 2014).

\subsection{Virtual Learning Environments}

Virtual learning environments (VLEs) are ubiquitous by now, so a brief comment to emphasize that the community should make use of these tools is in order. The next section will give an obvious example of how these can enable efficient and effective assessment design. It is well accepted in the higher education community that there are many potential benefits of a VLE, such as: (i) incorporation of quiz environments for both student self-assessment and efficient summative assessment; (ii) date releasing and conditional releasing of information linked to student behavior; (iii) maintenance of a database of student interaction, which can be used for monitoring and support; (iv) integration of unfair means tools such as Turn-it-in; (v) a single, convenient location for all module resources.

\subsection{Using Software for the Assessment of Control and Systems Skills}

Many topics within control and systems, when applied to realistic high-order systems, large data sets, or non-linear problems, require algebra and numerical computation that is not possible with pen and paper. Consequently, it is not easy to include interesting problems (closer to the challenges faced in industry) within a traditional examination scenario. University is aimed at developing and assessing higher level skills such as interpretation, analysis, and design, rather than number crunching, so it is worthwhile to consider how technology can be used to support assessment of the most important learning outcomes and circumvent the computational restrictions of pen, paper, and calculator. Within an industrial scenario, students would have access to software tools where appropriate, so it seems reasonable to allow similar tools within university assessment. In fact, assessment of the skill of using software to aid in problem solving is itself an important consideration.

Many excellent examples of how one can set up assessments that require students to apply their skills to complex control problems within an examination scenario already exist (Lynch and Becerra 2011). By providing students with full access to, for example, MATLAB and the relevant toolbox(es) for a given topic, the assessment of advanced 
concepts becomes readily possible. Students at Sheffield have commented that interaction with software was far and away the most valuable part of module assessment (Rossiter, Giarouris, Mitchell and Mckenna 2008), noting that it allowed them to focus on concepts and see and understand the impact of parameter changes quickly rather than being bogged down with algebra.

\subsection{Massive open online courses (MOOCs) and open resources}

The IFAC community has recognised the power of the internet for facilitating sharing of education resources amongst its members, and indeed more widely and thus, as discussed in section 2.2 , is actively supporting the creation and management of resources linked to control IFAC (2016). Nevertheless, a brief review of generic issues linked to learning and teaching would not be complete without some discussion of MOOCs, especially given their take up in control engineering. MOOCs can support blended learning (BLE 2009) and more specifically reach out to different classes of learners. Simple reasons, to quote the Futurelearn website (https://www.futurelearn.com/) are:

- Learn anything: Choose from hundreds of free online courses: from Language 8 Culture to Business $\&$ Management; Science $\&$ Technology to Health $\&$ Psychology.

- Learn together: Join an online course and meet other learners from around the world. Learning is as easy and natural as chatting with a group of friends.

- Learn with experts: Meet educators from top universities and cultural institutions, who'll share their experience through videos, articles, quizzes and discussions.

Indeed a key selling point of a MOOC is that it is free at the point of access and, to some extent, allows $24 / 7$ access to the learning resources. There has been a relative explosion in the number of MOOCs available in recent years and even a cursory search demonstrates that a large number of MOOCs in the control area already exist (e.g. (White et al. 2017; Tochan 2017; Matsuura et al. 2017; Egerstedt 2016; Albertos et al. 2017)) and thus readers may already want to ask to what extent can they make use of these to support their own teaching. A particularly popular MOOC in the control community is Egerstedt (2016) and also Albertos et al. (2017) is a course partnered to a prize winning book (Albertos et al. 2010) seeking to make control palatable to a broader audience. However, even a brief discussion on MOOCs must consider the negatives along with the positives.

(1) They require substantial money and time to do well. The first authors institutions estimate is close to $100 \mathrm{~K}$ dollars including professional production, videoing, editing and so forth which means that in effect each institution can afford to produce only a few per year.

(2) The monetary income is likely to be small or negligible in many cases and thus some greater good or other argument is needed to justify the cost.

(3) MOOC delivery platforms tend to be organised so that the material is available only on set intake dates, perhaps twice per year, and thus access is relatively limited in practice.

(4) In order to facilitate good learner experience, the discussions board (or student feedback) aspects of the course need to be well supported and a moderately successful MOOC attracting over a 1000 students may require significant staff support from the provider side, for which there is typically no payment!

In summary therefore, MOOCs are here to stay and no doubt are part of the future landscape but there is still significant debate to be had on how these can be financed and delivered effectively in the long term. 


\subsection{Summary}

(1) Lecture time should not be dominated by didactic delivery; rather students should be active.

(2) Provision of lecture recordings and pre-prepared videos gives support to students who benefit from seeing and listening to something several times and frees lecture time for more engaging activities.

(3) There is an opportunity for IFAC to facilitate the sharing of high quality resources (IFAC 2016).

(4) VLE tools are available to improve student access, feedback, record keeping, communication, monitoring, assessment, and so on.

(5) Allowing students access to software during examinations means being able to give more industrially relevant and interesting assessments.

(6) The landscape is changing fast and teaching staff will need to engage more actively with the potential uses of web based resources ranging from the many free ones on the IFAC repository (IFAC 2016) to more structured ones such as MOOCs.

This section, due to its brevity, has not discussed the growing recognition in the benefits of peer-to-peer learning (Pasik-Duncan 2015; Pasik-Duncan and Duncan 2002), the efficacy of games and competitions in improving engagement and learning (Saeedeh, Guilherme and Nina 2015), and the international growth in MOOCs (Egerstedt 2016).

\section{Integrating Online and Face-to-Face Learning and Teaching Environments}

Laboratories play a key role in student learning, as they provide a tangible experience of engineering in real life and the ability to learn by trial and error. This section focuses on how to ensure that students make the most of their time with hardware through effective preparation.

\subsection{Background}

In order for students to benefit fully from access to hardware, it is important that they prepare adequately. Hence, the requirement for students to do pre-lab activities closely related to the laboratory (Abdulwahed 2010; de Jong, Linn and Zacharia 2013) is relatively widespread good practice.

Academics at Griffith University have been working on incorporating online teaching tools to increase teaching efficiency as well as student engagement (Perez, Dormido and Vlacic 2011). They introduced a continuing online assessment of student assignments which, according to the feedback received from students, helped students to "gradually grasp the difficult material," "more easily handle analytical expressions," and "shorten the time spent on assignment writing." The course convener also benefits from this system, as a computer calculates the assignment score and provides prompt feedback to the students.

An online environment can provide many opportunities towards increasing student engagement. For example, Perez, Dormido and Vlacic (2011) reported on the outcomes from incorporating interactive, animated online tutorials into traditional classroom settings. These tutorials (addressing numerous control system examples, from the tank level and welding machine control to cooperative robot arms, space telescope, and supersonic jet control) have been developed with a simple user interface and made available to students since early 2006. In addition to increasing average scores over the period 2006 to 
2014, student feedback from course evaluations shows improving responses to the question: Overall, I am satisfied with the quality of this course. This is illustrated in Figure 1, which shows the historical trend from 1997 to 2014 of the mean response to this question in both the Introductory Control Systems course and the final year Digital Control Systems Engineering course at Griffths University in Australia. It may be interesting for control colleagues who often use MATLAB to note that the University of Sheffield carried out a similar project with MATLAB teaching and found this to be equally effective (Rossiter and Gray 2010).

\subsection{Online Assessment of Lab Preliminaries}

Both the Introductory Control Systems course and Digital Control Systems Engineering course are lab intensive. Consequently, lecture and lab topics are closely related and sequenced. Typically, the lecture topic taught in the current week is explored and examined during the lab session held the following week. This would mean that a theoretical concept covered in lecture during week 2 would be explored and examined in the lab environment in week 3 , while the lecture topic of week 3 would be explored in the lab session of 4, etc. From the view point of study commitments, students are expected to prepare for each incoming lab session by working on lab preliminaries (assignments). For example, after a new theoretical concept is introduced in week 2 , students are required to work, on their own, on the related lab preliminary for the reminder of that week in order to be ready for undertaking lab experiments on the same topic during week 3 .

Up until 2011, the beginning of each lab session was dedicated to giving feedback to students based on review and assessment of their lab preliminaries. Assessment of the lab preliminaries was under significant time pressure due to the need for providing students with timely feedback.

Since 2011, the lab preliminaries have been given to students as an online assessment item in the Blackboard Learning Management System. They consist of both theoretical questions and analytical problems, all presented in the form of a multiple-choice questionnaire designed to test correct process in deriving solutions, with analytical problems being decomposed into a sequence of steps and sub-questions. Students are requested to submit their results online by a given deadline, well prior to the incoming lab session. Thanks to Blackboard's Adaptive Release tool, students are provided with immediate access to detailed step-by-step solutions to analytical problems upon submission of their results. Also upon submission, a lab manual for the incoming lab session is released.

\subsection{Benefits Obtained: Improving the Pre-Lab Experience}

Since students' work on lab preliminaries are now automatically graded and the correct analytical solutions provided, questions received from students at the beginning of each lab session are more meaningful than before (and much fewer in a number). With more time available during the lab sessions and increased understanding of the experiments due to the pre-lab preparation, students are able to produce higher quality lab reports. The only tangible measure obtained so far is a course satisfaction feedback received from students. Figure 2 shows the historical trend of the mean values obtained from three courses with the significant online assessment components.

Although the improved pre-lab experience has resulted in fewer questions at the beginning of each lab session, care must be taken in implementing this system during the first week of course delivery. In particular, many students are not familiar with such an online learning and teaching environment and show trepidation in facing it for the first time. This has been shown as very true for each and every course which applies online 
assessment, regardless of whether the course is about control systems or any other topic. Thus, students must be taken through the online learning and teaching environment at the very beginning of the course, before any assessment takes place, in order to raise their confidence in being able to work through the lab preliminaries independently and receive the full benefits of engaged learning.

\subsection{Future plans}

Plans for future improvements overlap with the previous section on lectures. There is evidence (for example, from recent work in Southampton on how quality video and animation could improve student preparation (Memoli 2011)) that including familiarization 'lectures' for anything new, such as an online quiz environment, helps improve student engagement/learning and reduces the 'fear factor'. In this case, for example, modern technology enables the cheap production of video and thus academics at both Griffiths and Sheffield are planning to introduce mini-lab introductory lab lectures (of 5-7 minutes each) to help students better prepare for incoming lab sessions. This enables students to become familiar, in advance, with the hardware set up and activities required.

\section{Using Technology to Improve the Efficacy of Laboratories}

Remote experimentation for engineering education can be considered a mature technology (widely implemented) (RELOAD 2010; Qiao 2012; Ma and Nickerson 2006). It enables access to real hardware and thus an authentic learning experience outside of the classroom timetable and without requiring physical attendance at a particular location. A simulated or virtual laboratory provides an authentic representation of, or interaction with, a real scenario, whereas a remote laboratory gives access to and control of actual equipment (Dormido 2004). However, the process of transforming a classic control experiment into an interactive web-based laboratory is not yet an easy task (Vargas 2011), or indeed an art form which has established norms, as will be summarized in this section.

\subsection{Background and General View}

It is well known that education in science and engineering disciplines requires practical experimentation. While this has been carried out in laboratories or in the field for ages, the use of computers has recently introduced new approaches. Simulated and remote laboratories are one of the new possibilities technology offers to cover the experimentation need in scientific and technical education programs. A simulated or virtual laboratory (VL) corresponds to a computer application providing a graphical representation not only of the objects under experimentation, but also of the instruments that would be used to perform the experiment in the real world. On a remote laboratory (RL), the control and observation of the real physical instruments and objects under experimentation is mediated through a computer, while an adequate remote access to that computer is provided through a specific communication network (Harry 1999).

Web-based laboratories is a term that is commonly used to refer to virtual and/or remote laboratories (VRLs) without distinction. VRLs are mainly used in two different scenarios. The first involves traditional face-to-face universities. In these cases, Web-based laboratories are used as a complement to hands-on laboratories practices, although this is still not as popular as it could be (Gustavsson 2009). Thanks to their use, while students still have to perform experimental activities in a real lab, they can spend additional time experimenting from their own homes. The second scenario is offered by distance 
universities. In these cases, VRLs are used as a substitute for traditional labs, since hands-on experimentation in a real laboratory is not always possible.

While some courses only offer virtual or remote laboratories, it is commonly accepted that VRLs work better when both virtual (simulated experiment) and remote (real, remotely-controlled experiment) laboratories are offered together (de Jong, Linn and Zacharia 2013). In fact, each of these two parts can serve different purposes. Although simulations can be very useful, VLs cannot completely replace real laboratories. This is especially true in some scientific fields such as physics or control engineering, where the behavior and response of the real elements used in the experiments are crucial (Alhalabi et al. 2000). On the other hand, since they use real equipment, RLs (which provide real laboratory facilities to students such as the simulation software does (Gorrel 1992)) may constitute a better substitute or complement to real hands-on experiments. However, VLs may still be used to serve as initial experimentation facilities for: 1) providing a first contact with the phenomena under study, 2) familiarizing students with the use of virtual and remote applications, and 3) offering theory-based results of the experiments.

Since RLs provide real experimental results and VLs offer theoretical ones, combining the two allows students to compare reality with theory, which is one of the fundamental steps of the scientific method. Therefore, a web-based laboratory consisting of both a simulation and the remote experiment, offers a more complete learning experience to the students (Abdulwahed 2010). Web-based laboratories, in any of their forms, are now well established in several scientific and technical disciplines, since they help to illustrate phenomena that require costly or difficult-to-assemble equipment (Goodwin et al. 2011). Examples of this can be found in (Chang et al. 2005; Sivakumar 2005).

\subsection{Laboratory Activity Emulation}

A popular alternative to RLs is an animated simulation environment (Foss et al. 2006; Guzmand 2006; Khan and Vlacic 2006; Perez, Dormido and Vlacic 2011); that is, one which emulates real equipment and has the appearance of being authentic (Goodwin 2010), despite being a simulation. These can be used in isolation, for example as part of a learning activity or assignment, or to support pre- and post-laboratory activities (Abdulwahed 2010) (that is, to emulate the activities, concepts, and questions in an actual laboratory). An obvious advantage is that multiple students can access such an activity simultaneously, as well as anytime/anywhere.

Simulations can be coded relatively quickly using MATLAB tools (Rossiter 2012) and, as such, are readily available to students on their own laptops. They can also be used easily within lectures to visually reinforce key concepts. A simple, self-explanatory example is given in Figure 3. The advantage of using MATLAB tools is that a module lecturer with minimal skills in hardware or the web can edit activities quickly to suit the requirements of different students or modules.

\subsection{Other Solutions for Providing Online Experimentation Tools}

Apart from VLs and RLs, there are also other approaches to the distance experimentation problem in science and engineering distance learning courses. One of these solutions are the interactive screen experiments (ISEs) (Hatherley, Jordan and Cayless 2009). These tools are highly interactive nonlinear movies that run under user control by clicking and dragging on the experimental equipment displayed in the movies (Memoli 2011). These movies can be played in an ordinary web browser with a free Shockwave or Flash plugin, similarly to a Java applet. An ISE consists of many hundreds of photographs of an actual laboratory experiment designed to capture all possible states of the apparatus. It 
is a kind of highly interactive movie where the student can control the development of the plot. ISEs are real experiments showing real phenomena, not simulations. When the student runs an ISE, the effect is as similar as possible to running the real experiment by remote control. The difference for the laboratory provider is that there is no limit to the number of students who may simultaneously run the experiment and the real equipment itself is used only once.

ISEs do present one major drawback when compared to RLs; namely, that since the experimental data in ISEs are recorded (and the real equipment is never used again), students always obtain exactly the same results when a particular state of the experiment has been set. On the other hand, RLs may return different values when measurements are taken even under identical conditions. The human resource required to produce an effective ISE should also not be under-estimated; video/image collection has to be very precise and is very time consuming, not to mention the need for expertise, and time, in coding up the web interface.

Another solution, applied by some open universities, is to send each student the required material to perform the experiments and then ask them to use it to complete some experimental activities. Although this solves the problem of removing traditional experimentation in distance education courses, this solution can only be applied for a few particular cases in which the required material is not very expensive, heavy, bulky, or fragile, due to shipping constraints.

Other resources such as videos and interactive videos should not be considered as alternatives to ISEs, VLs and RLs but as a complement to them. While the former may serve as a tool for providing theory lessons, the latter try to cover the experimental part of the subjects, and not the theoretical one.

\subsection{Virtual and Remote Laboratories in Physics and Engineering}

The two fields in which VRLs have been most widely applied are Physics and Engineering. Therefore, it is worth paying special attention to the state of the art of web-based labs in these two particular fields, where the vast majority of the efforts regarding the development, implementation, and use of these tools have been focused during the last few years. This subsection gives an overview of the most relevant works related to these fields.

\subsubsection{Virtual and Remote Laboratories in Physics}

Physics simulations have experienced a huge increase in number and quality thanks mainly to Java applets. In (Christian and Belloni 2004; Christian, et al. 2011), hundreds of simulated experiments and processes in different fields of physics are presented (all of them developed using Easy Java Simulation). Some of them, and many other simulations, are available for free, thanks to the work presented in (Kocijanic 2002). However, real experiments are not specifically considered in these works. Also, in spite of the huge number and outstanding quality of the available simulations, the web page in (Christian, et al. 2011) is conceived as a simple repository of physics simulations, and not as a web-enabled environment for virtual experimentation.

Other recent works focus on the introduction of computers into physics laboratories for data acquisition and analysis (Kocijanic 2002; Schauer, Kuritka and Lustig 2006), but not for distance learning purposes. Moreover, most of the remote laboratories for physics-related experimentation are individual experiments (Park 2005; Schuaer, Lustig and Ozvoldova 2006), or are limited to a particular field, such as optics (Chang et al. 2005; Gurkan, Mickelson and Benhaddou 2008) or electronics (Macias and Mendez 2007; 
Moon 2008). None of the latter works offer the simulated counterparts of the remote experiments or a web-enabled environment supported by learning management system (LMS) facilities. Finally, just in (Grober 2008, 2007; de la Torre 2011), each experiment is presented in a similar way to a traditional student lab: introduction, theory, exercises and problems, laboratory activities, analysis, discussion, and reference material.

It is also important to mention the lack of RLs dedicated to the topic of Physics. In (Ma and Nickerson 2006), sixty papers about hands-on labs, VLs, and RLs are analyzed. While twenty of them were dedicated or related to RLs, only one was about physics whereas fifteen were about engineering (electrical engineering, mainly). In (Gravier 2008), fortytwo works about the same topic are studied and, while eight covered the physics field, engineering was again far ahead with twenty-six papers dedicated to that discipline. Figures 4 and 5 illustrate these numbers.

\subsubsection{Virtual and Remote Laboratories in Engineering}

As previously stated, (Ma and Nickerson 2006) analyzed sixty papers and, regarding engineering disciplines, fifteen of them were dedicated or related to VLs while twenty were to RLs (Figure 4). In (Gravier 2008), twenty-six papers dedicated to RLs in engineering were found (Figure 5). As a result, we can conclude that both VLs and RLs are widely used in engineering courses. Other works, not analyzed in (Ma and Nickerson 2006) nor in (Gravier 2008), such as (Casini et al. 2007), present a solution for operating remote laboratories from a bootable device (a CD, for example) that allows selecting and controlling a wide variety of different experimental systems. While this avoids the problem of integrating the RLs into a web page, it also limits their deployment.

More interesting and up-to-date works regarding VRLs in Engineering can be found. A framework for rapid remote experiment implementation in the field of automatic control is presented in (Hercog 2007), based on the use of MATLAB/Simulink for the control algorithm development and on LabVIEW for the user front-end application. In (Stefanovic 2011), the architecture and characteristics of a laboratory experiment for control of the coupled water tanks (using LabVIEW in both the server side and as the user graphical interface) is explained. The work in (Barrios et al. 2013) describes the development, implementation, and preliminary operation assessment of multiuser network architecture to integrate a number of Remote Academic Laboratories for educational purposes on automatic control. The solution is based on the use of graphical user interface (GUI) developed with Easy Java Simulation (EJS) and MATLAB and/or LabVIEW for controlling the devices of the remote laboratory. This solution is very popular and it is also applied in works such as (de la Torre 2011; Fabregas 2011; Guinaldo 2013; Dormido, Vargas and Sanchez 2012; Vargas 2011; MIT 2016; Hardison 2008). In (Lazar and Carari 2008), a networked control-system laboratory for the remote control of processes is presented and two different plants are used for the experiments: once for level-flow experiences and a heat exchanger. The work in (Fabregas 2011) presents a VRL with the ball and hoop system in which users can control: 1) the position of the hoop and 2) the angle deviation of the ball. The same solution as in (Barrios et al. 2013) and (Fabregas 2011) is applied in (Guinaldo 2013) for creating a VRL with the ball and beam system, where several control strategies are implemented to control the position of the ball over the beam: PID, fuzzy, and reset control. Finally, (Grau and Bolea 2008) maintains the same architecture and tools as the latest works and presents yet another remote laboratory about water level control, which is probably the most exploited system for the creation of web-based remote labs. Another example of this can be found in (Dormido, Vargas and Sanchez 2012). Finally, (Vargas 2011) also presents two more VRLs about control engineering: a DC motor (which can be controlled either in position or in velocity) and a heat-flow system. 


\subsection{Conclusions About the State of the Art in Virtual and Remote Laboratories}

The conclusions in (Ma and Nickerson 2006) focus on stating that most of the laboratory articles were engineering-related and on discussing the effectiveness of VRLs. On the other hand, the work in (Gravier 2008) concludes, from their literature review, that there were still "four major issues for the leverage of remote laboratories." And that these issues "are reusability, interoperability, collaborativeness and convergence with Learning Management Systems." Other works, such as (Gomes 2009; Chen, Song and Zhang 2010), point out the same issues as current trends in VRL development.

While the last of these four issues (the one regarding integration with LMS) has been resolved when working under certain specific circumstances (San-Cristobal 2010), the other three are still fully open. More specifically, (San-Cristobal 2010) presents a solution for embedding VRLs developed using the iLab solution (MIT 2016; Hardison 2008) into SCORM packages, which are easily integrated into several LMSs but do not support interaction between the VRLs and the LMS itself. However, the work in (de la Torre 2013; de la Torre et al. 2013) not only offers an easy integration of VRLs, based on a different solution and technology (EJS), into a LMS (in such a way they can "communicate" or interact), but also a solution to the reusability and collaborativeness issues. Another similar, but more limited, work is (Magdin, Cpay and Halme 2012), where an integration of LogicSim applets into Moodle is presented. It is more limited due to two main reasons: 1) LogicSim applets only serve for logic circuit VLs and 2) the additional features obtained by integrating the applet with the LMS are very few.

The work in (Gravier 2008) shows that Java is the most used program to create the GUI of the middleware through which information is exchanged between local and remote computers (see Figure 6). As the framework proposed in (de la Torre 2013) uses the same technology (Java), the tools presented in that thesis are as reusable as possible for many of those works.

Another literature review about VRLs (Chen, Song and Zhang 2010) concludes that: 1) "There are lots of virtual and remote laboratories developed with LabVIEW, Java Applet and Flash" and 2) "To develop a remotely accessible laboratory; the developers have to master computer hardware and software, data digitization and collection, data transmission and visualization, and network. An engineering education laboratory developer usually has expertise in their research field, but not necessarily in remote laboratory development. The development of a unified user friendly remote laboratory publishing tool for laboratory developer is in great demand." The first conclusion supports the information provided in Figure 6 (extracted from (Gravier 2008)), which means that the work in (MIT 2016) is as reusable as possible since the proposed solution is applicable in VRLs developed with EJS. However, this conclusion should be tempered with the observation that practice in the computer science community can change very fast and thus a new survey is required to represent the current situation. The second conclusion is a key point and (de la Torre 2013) is extremely focused in making life easy to instructors who want to develop their own VRLs (or reuse existing ones) for their courses.

Finally, given the amazing increase in the importance and use of mobile devices such as tablets and smartphones, a recent issue is making VRLs compatible with all kind of devices so they really can be used anywhere, anytime. The work in (Esquembre and Garcia 2013) has already given the first steps to solve this problem by making EJS applications compatible with all kinds of devices thanks to the use of the Javascript technology instead of Java. 


\subsection{Staff Resources and Interim Conclusions}

This section has demonstrated that the modern Internet enables the provision of remote and virtual laboratories and that, while this is relatively straightforward in principle, there are still many practical obstacles (Rossiter 2011), especially for RL.

(1) For slow processes (equipment with long time constants), an effective queueing or booking mechanism is needed on the server and this may be non-trivial for academics to facilitate.

(2) Queueing will still be needed for equipment with fast time constants due to likely overlap in students 'free periods.'

(3) Poor access and/or long waiting times may be inevitable with large classes and this can cause widespread student frustration and disengagement! The alternative of arranging some form of booking system introduces ongoing management and coding complexity which can be difficult.

(4) Reliability is critical and there are multiple possible failure points (computer, power, hardware components, lighting, etc.). The monitoring and maintenance load on technical staff may be far greater than staff originally expect.

A key requirement for VRLs is good accessibility and thus one might favor laboratories that multiple students can access simultaneously via the Internet (Khan and Vlacic 2006; Guzmand 2006). However, academics responsible for delivering virtual laboratories have other factors to consider:

- The better and more accessible the interface, the more likely that the development work is significant and/or requires substantial software/hardware skills. Staff with limited resources/skill may find that less accessible interfaces which allow simpler coding are pragmatic alternatives; for example, MATLAB GUI tools are relatively easy to use and share (Rossiter 2012).

- Module leaders like to tweak their module activities regularly and hence there are advantages of being able to author/edit their own VRLs rather than being reliant on a costly or unavailable expert.

- Off the shelf or free to access laboratories is cheap to implement and may be high quality, but the IFAC community does not yet have an effective mechanism for sharing these alongside independent evaluations.

\section{Take Home Laboratories}

Data acquisition and control hardware is progressively becoming less expensive, raising the potential for providing students with meaningful educational hardware at a low cost. For example, a few years ago, such capability was provided by an expensive IO board on the computer whereas nowadays one can drive hardware through the USB port via a simple Arduino-based interface (Hill 2015; Reck and Sreenivas 2015; Egerstedt 2014). In terms of education, this opens the door to a significant change in how students access laboratories, since it is now possible for students to be provided with their own hardware for a range of activities, thus reducing the need to access department facilities and timetable scheduled laboratory sessions.

As a teaching aid, the provision of data acquisition and control hardware on an individual basis has received little attention until recently, in large part because of the prohibitive costs involved. However, this is beginning to change, particularly with the advent of low cost data acquisition and control units, such as National Instruments' (NI) myDAQ, which has begun to establish itself as a teaching aid in the educational sector, particularly in electrical and electronics engineering courses (Chesnutt and Baker 2009; 
Walters 2011; Meng-Jun 2011). The adoption of this hardware by the systems and control community has been slower, but is starting to happen, particularly with the advent of NI's 'miniSystems' that utilize the myDAQ platform to provide a portable and low-cost replica of a range of real-world systems. Current examples include miniature vertical take-off and landing vehicles, smart power grids, and flexible structures. Of particular note is that the vast cost reductions for simple laboratory equipment (Reck and Sreenivas 2015) gives universities opportunities to provide multiple sets (say 50-100), which was just not possible when a single piece of equipment could cost $£ 5-10 \mathrm{~K}(\$ 7.5-15 \mathrm{~K})$; this multiplicity vastly improves student access to laboratory experience.

Inspired by these examples, Sheffield staff (Taylor, Jones and Eastwood 2013) have recently developed their own take-home hardware to provide systems engineering students with a challenging and portable control problem. This hardware is shown in Figure 7 and consists of a miniature three-degree-of-freedom (3DOF) helicopter, interfaced to a $\mathrm{PC}$ via a NI myDAQ. The helicopter chassis consists of two independently controlled fans connected via a rigid link. This link is free to pitch around an axis that is pivoted at the end of a second linkage that provides mechanical assistance via an adjustable counterweight mounted at its far end. This linkage is free to rotate about the horizontal plane, and is mounted upon a vertical shaft that spins freely within a cylindrical housing. This housing connects to a signal conditioning board via a standard D-type connector. This allows easy assembly, and disassembly of the take-home kit, which is stored within a padded toolbox for easy and safe travel between home and campus. The helicopter is instrumented with sensors that measure the angular changes about the three primary axes of rotation. The entire parts cost of each kit was under $£ 300(\$ 450)$, making it possible to provide each student in the course with their own kit, on a loaned basis.

The system is dynamically rich, containing a mixture of continuous and discrete-time dynamics. It is nonlinear and displays significant dynamic coupling between the inputs to each fan and each of the measured linkage angles. The system provides students with a challenging control problem, requiring mastery of techniques such as modelling, state-estimation, and multivariable control. Owing to the modularity of the design, the helicopter chassis can be replaced by other systems that connect to the signal conditioning board via the same connector. One such system is a simple IO board consisting of LEDs, a potentiometer, and a switch, which is used to teach basic data-acquisition techniques before introducing the helicopter assembly. Student feedback on the inaugural use of the take-home hardware has been extremely positive. In terms of the student interaction with the hardware, two-thirds of the students used the equipment elsewhere on campus, other than in the classroom sessions, and over three-quarters of the students reported using the hardware at home. Of those students who had not used the hardware at home, when questioned as to why this was the case, the typical response was either that they had finished the exercises in class or had completed the tasks elsewhere on campus. Based on this initial experience, we conclude by suggesting the take-home paradigm has significant potential as a teaching aid within within the systems and controls curriculum.

\section{Broadening Our Students Perspectives}

The concept of what it means to be an engineer is changing rapidly. No longer do employers want someone who has just attended traditional classes in engineering topics; today's engineers are expected to be multi-disciplinary, with at least some knowledge of finance, biology, the environment, and so on. Consequently, there is a need to re-invent our traditional control courses (Murray 2013). To what extent do these courses encourage students to think of their discipline outside the conventional boundaries? To what 
extent do we offer a control and systems module that is attractive to students from outside engineering? There is already some evidence in the literature (Murray 2013, 2004) of successful models for achieving this. There is a need for a dialogue in IFAC about how we take this evangelization forward and determining the correct balance between concepts/application and rigorous mathematical underpinning.

This article, with its focus on good practice in control education, would not be complete without including a story of success in reaching middle and high school students and teachers through the joint efforts of the technical committees on education of IEEE CSS, IFAC, and AACC. This year marked the fifteenth anniversary of the "Ideas and Technology of Control Systems" workshops, which are held biannually in conjunction with the ACC, CDC, and IFAC Meetings and Congresses. They strive to bring control system concepts and technologies to the awareness of middle and high school students and teachers. The longevity of the control field, which spans science, technology, engineering, and mathematics (STEM), depends on continuous success in attracting the most gifted young people to the profession. With the understanding that early exposure is the key to achieving that goal, the efforts to bring control systems to middle and high school students and their teachers were launched for the first time at ACC 2000 in Chicago.

These educational outreach efforts promote increased awareness among students and teachers of the importance and cross-disciplinary nature of control and systems technology. The idea is that education is, at all levels, an inclusive process: it should integrate scholarship, teaching, and learning, both horizontally and vertically. Over the past fifteen years, this model of a sustainable outreach partnership between our control communities and the local school districts in the places where our major conferences are held has been established and followed by other organizations and societies. This outreach partnership has provided a vehicle for demonstrating the importance of control. The workshop activities include presentations by control systems experts from the control community, informal discussions, and the opportunity for teachers to meet passionate researchers and educators from academia and industry.

Closely related to the workshops, a discussion on "Plain Talks" was initiated. The goal was to develop short and inspirational presentations for teachers and students interested in systems and control, but also for those in non-control engineering communities. One of the major challenges for the control communities is to enhance its own public image and convey the essence and contribution of the field to outsiders, and so this component of the outreach effort has been focused on what we can do to be better communicators of our field to the broader community.

Also relating to the workshops, many Special Sessions on Education have provided a forum for dialogue on innovative methods of teaching and integrating research and teaching. The recent discussion at these well-attended sessions has focused on the multitude of challenges and opportunities that are presented to students preparing for careers in science and engineering.

One of the most important challenges for scholars and educators from academia and industry is to find the best way of cultivating student interest in science, math, and engineering. During the last fifteen years, over 10,000 middle and high school students and their teachers, as well as undergraduate students, have been reached through our educational activities. Over 150 passionate senior and junior researchers, representing both academia and industry, have been engaged in these educational activities as speakers and presenters. The history of these workshops and special sessions on innovative teaching methods, textbooks, and digital textbooks, held at almost every control conference, has been well-documented (Workshops 2016). These workshops also promote important control applications in nontraditional areas, such as financial engineering and biomedical engineering (Pasik-Duncan and Verleger 2009; Pasik-Duncan 2004). 


\section{Conclusions and Future Opportunities}

This article has given an account of some good practice in the area of control education. There was brief discussion of areas that are shared across all disciplines, such as lecturing and assessment, followed by a more detailed discussion of topics that are highly relevant to control, such as virtual and remote laboratories. A summary of the key points is as follows.

(1) There is a growing acceptance of the potential of virtual and remote laboratories to enhance student engagement/learning and to supplement formal laboratory sessions. Universities would now be expected to explore how such resources can enhance their provision. However, it is noted that substantial expertise is needed to create an effective and reliable remote laboratory and thus in the first instance a focus on virtual laboratories is sensible.

(2) Numerous excellent virtual laboratories are freely available on the Internet, but could benefit from independent evaluation and coordination. Virtual laboratories require less expertise and time to develop, with many good examples already in existence. IFAC can potentially play a role in quality benchmarking and distribution through its resources site IFAC (2016).

(3) There is a consensus that laboratories are more effective when paired with high quality pre- and post-laboratory resources and activities.

(4) It is increasingly straightforward and cost effective to design, build, and distribute cheap laboratory kits that all students can use outside of the classroom. One would envisage this activity growing significantly in the next few years.

(5) There are many opportunities for the IFAC community to provide learning resources that are easy to use and learn from. In turn, this presents an opportunity to rethink the role of the traditional lecture in education. The majority of staff will need to move away from over reliance on the conventional didactic lecture to a more blended delivery style, making use of a variery of teaching techniques and resources.

In conclusion, with the ever-increasing power and availability of mobile devices such as tablets and smartphones, students are able to access internet based resources anytime and anywhere (Esquembre and Garcia 2013) and this provides tremendous opportunities to teachers. It is now timely for organizations such as IFAC to take a strong lead in providing guidance or ratification of core educational resources on the Internet.

\section{Acknowledgments}

Removed for review to ensure anonymity.

\section{References}

Abdulwahed, M., 2010, Towards enhancing laboratory education by the development and evaluation of the trilab concept. PhD thesis, Univ. Loughborough.

ABET, Accreditation in the USA, http://www.abet.org.

Albertos, P. and Mareels, I., 2010 Feedback and Control for Everyone,Springer.

Albertos, P., Dynamics and Control (edX), Created by Universitat Politcnica de Valncia, Delivered by:EdX.

Alhalabi,B., D. Marcovitz, K. Hamza, and M. Petrie, 2000, Remote labs: An innovative leap in the world of distance education. In Proc. 4th Multi Conf. on Systemic, Cybern. and Informatics, pages 303-307. 
Barrios,A., S. Panche, M. Duque, V. H. Grisales, F. Prieto, J. L. Villa, P. Chevrel, and M. Canu, 2013, A multi-user remote academic laboratory system. Computers \& Education, 62:111-112.

Cameron, I., 2009, Pedagogy and immersive environments in the curriculum. In Blended Learning conference, pages 290-294.

Casini,M., D. Prattichizzo, and A. Vicino, 2007, Operating remote laboratories through a bootable device. IEEE Transactions on Industrial Electronics, 54:3134-3140.

Chang, G.W., Z. M. Yeh, H. M. Chang, and S. Y. Pan, 2005, Teaching photonics laboratory using remote-control web technologies. IEEE Transactions on Education, 48(4):642-651.

Chen, X., G. Song, and Y. Zhang, 2010 Virtual and remote laboratory development: A review. In Earth and Space, Engineering, Science, Construction, and Operations in Challenging Environments, pages 3843-3852, doi: 10.1061/41096(366)368.

Chesnutt, C. and M.C. Baker, 2009, Incorporation of NI myDAQ exercises in electric circuits. In ASEE Gulf-Southwest Annual Conference.

Christian, W. and M. Belloni, 2004, Physlet Physics. USA: Prentice Hall.

Christian,W., F. Esquembre, and L. Barbato, 2011, Open Source Physics. Science, 334:1077-1078, doi: 10.1126 /science.1196984.

Crouch, C.H. and E. Mazur. Peer Instruction: Ten Years of Experience and Results. Am. J. Phys., 69:970-977, 2001

de Jong, T., M. C. Linn, and Z. C. Zacharia, 2013, Physical and Virtual Laboratories in Science and Engineering Education. Science, 340:305-308.

de la Torre,K., J. Sanchez, S. Dormido, J.P. Sanchez, M. Yuste, and C. Carreras, 2011, Two web-based laboratories of the FisL@bs network: Hookes and Snells laws. European Journal of Physics, 32:571-584.

de la Torre, L., 2013, New Generation Virtual and Remote Laboratories: Integration Into Web Environments 2.0 With Learning Management Systems. PhD thesis, UNED.

de la Torre,L., R. Heradio, C. A. Jara, J. Sanchez, S. Dormido, F. Torres, and F. Candelas, 2013, Providing Collaborative Support to Virtual and Remote Laboratories. IEEE Transactions on Learning Technologies.

Dormido, S., 2004, Control learning: Present and future. Annual Reviews in Control, 28:115-136.

Dormido, S. and H. Vargas an J. Sanchez, 2012, AutomatL@bs Consortium: A Spanish Network of Web-Based Labs for Control Engineering Education. In A. Azad, M. E. Auer, and V. J. Harward, editors, Internet Accessible Remote Laboratories: Scalable E-Learning Tools for Engineering and Science Discipline, chapter 11, pages 206-225. IGI Global.

Dormido,S., J. Sanchez, H. Vargas, L. de la Torre, and R. Heradio, 2012, UNED Labs: A network of virtual and remote laboratories. In J. G. Zuba and G. Alves, editors, Using Remote Labs in Education, chapter 12, pages 253-270. University of Deusto Publications.

Egerstedt, M., 2014, Low-Cost Educational Robots. Project with National instruments and Mathsworks.

Egerstedt, M., 2016, MOOC on Control of Mobile Robots. https://www.coursera.org/course/conrob.

Eichlere, A., C. Hoffman, C. Kautz, and H. Werner, 2013, Design of tutorial activities and homework assignments of a large enrollment introductory course in control systems. In IFAC symposium on Advances in Control Education.

ENAEE, European network for accreditation of engineering education. http://www.enaee.eu.

Esquembre, F. and F. J. Garcia, 2013, Creating simulations for tablets using Easy Java(script) Simulations. In 18th Multimedia in Physics TELL Conference.

Fabregas,E., G. Farias, S. Dormido-Canto, S. Dormido, and F. Esquembre, 2011, Developing a remote laboratory for engineering education. Computers \& Education, 57:1686-1697.

Fidler,A., A. Middleton, and A. Nortcliffe, 2006, Providing added value to lecture materials to an iPod generation. In 6th Conference of the International Consortium for Educational Development.

Foss, B., O.Solbjrg, T. Eikaas, and F. Jakobsen, 2006, Game playing in vocational training and engineering education. In IFAC symposium on Advances in Control Education.

Gomes, L., 2009, Current trends in remote laboratories. IEEE Transactions on Industrial Electronics, 56:4744-4756.

Goodwin, G.,2010, Virtual laboratories for control systems design. http://www.virtual- 
laboratories.com/.

Goodwin,G.C., A. M. Medioli, W. Sher, L. B. Vlacic, and J. S. Welsh, 2011, Emulation-based virtual laboratories: A low-cost alternative to physical experiments in control engineering education. IEEE Transactions on Education, 54:48-55.

Gorrel, J., 1992, Outcomes of using computer simulations. Journal of Research on Computer Education, 24:359-366.

Gould, S., 2013, Tech-savvy classroom aims to transform learning. http://yaledailynews.com/blog/2013/01/14/tech-savvy-classroom-aims-to- transformlearning/.

Grau, A. and Y. Bolea, 2008, Remote Laboratory for Control Engineering Degree. In Proc. 17th World Congress of the International Federation of Automatic Control (IFAC).

Gravier,C., J. Fayolle, B. Bayard, M. Ates, and J. Lardon, 2008, State of the art about remote laboratories paradigms foundations of ongoing mutations. International Journal of Online Engineering, 4(1).

Grober,S., M. Vetter, B. Eckert, and H. J. Jodl, 2007, Experimenting from a distance - remotely controlled laboratory (rcl). European Journal of Physics, 28:127-141.

Grober,S., M. Vetter, B. Eckert, and H. J. Jodl, 2008, Remotely controlled laboratories: Aims, examples and exercises. American Journal of Physics, 76:374-378.

Guinaldo,M., L. de la Torre, R. Heradio, and S. Dormido,2013, A Virtual and Remote Control Laboratory in Moodle: The Ball and Beam System. In Proc. 10th IFAC Symposium on Advances in Control Education.

Gurkan,D., A. Mickelson, and D. Benhaddou, 2008, Remote laboratories for optical circuits. IEEE Transactions on Education, 51:53-60.

Gustavsson,I., K. Nilsson, J. Zackrisson, J. Garcia-Zubia, U. Hernandez-Jayo, A. Nafalski, Z. Nedic, O. Gol, J. Machotka, M. I. Pettersson, T. Lago, and L. Hkansson, 2009, On objectives of instructional laboratories, individual assessment, and use of collaborative remote laboratories. IEEE Transactions on Learning Technologies, 2(4):263-274.

Guzman, J., K. Astrom, S. Dormido, T. Hagglund, and Y. Piguet. Interactive learning modules for pid Control. In IFAC symposium on Advances in Control Education, 2006.

Hardison,J.L., K. DeLong, P. H. Bailey, and V. J. Harward, 2008, Deploying interactive remote labs using the ilab shared architecture. In Frontiers in Education Conference.

Harry, K., 1999, Higher education through open and distance learning. Routledge.

Hatherly,P.A., S.E. Jordan, and A. Cayless, 2009, Interactive screen experiments innovative virtual laboratories for distance learners. European Journal of Physics, 30:751-762.

Hercog,D., B. Gergic, S. Uran, and K. Jezernik, 2007, A DSP-Based Remote Control Laboratory. IEEE Transactions on Industrial Electronics, 54:3057-3068.

Hill, R., 2015, Hardware-Based Activities for Flipping the System Dynamics and Control Curriculum (I). In $A C C$.

Huxham, M., 2005, Learning in lectures: do interactive windows help? Active learning in higher education, 6:17-31.

Hwang, F.K., 2009, Ntnu virtual physics laboratory: Java simulations in physics. In Multimedia in Physics Teaching and Learning Conference.

IFAC, IFAC links repositories. http://www.aurova.ua.es/tc94repository/tags.php/CC9-Social, 2016.

Kawski, M.,2013, Control and Mathematics Curricula. In IFAC symposium on Advances in Control Education.

Khan,A. and L. Vlacic. Teaching control: benefits of animated tutorials from viewpoint of control students. In IFAC symposium on Advances in Control Education, 2006.

Khan academy. https://www.khanacademy.org/.

Kocijancic,S., 2002, Online experiments in physics and technology teaching. IEEE Transactions on Education, 45:26-32.

Lancaster, S. and D. Read, 2013, Flipping lectures and inverting classrooms. Education in Chemistry, pages $14-17$.

Lazar, C., and S. Carari, 2008, A Remote-Control Engineering Laboratory. IEEE Transactions on Industrial Electronics, 55:2368-2375.

Lynch, S. and V. Becerra, 2011, MATLAB assessment for final year modules. In The use of 
MATLAB within engineering degrees. HEA workshop and seminar series.

Ma, J. and J. V. Nickerson, 2006, Hands-on, simulated, and remote laboratories: A comparative literature review. ACM Computing Surveys, 38(3).

Macias, M.E. and I. Mendez, 2007, elab - remote electronics lab in real time. In 37th Annual Frontiers In Education Conference - Global Engineering: Knowledge Without Borders, Opportunities Without Passports (FIE '07), pages S3G12-S3G17, doi: 10.1109/FIE.2007.4418154.

Magdin,M., M. Cpay, and M. Halme, 2012, Implementation of logicsim in lms moodle. In IEEE International Conference on Emerging eLearning Technologies and Applications.

Mathtutor, 2012, www.mathtutor.ac.uk.

Matsuura, J.P. and Afonso, R.J.M., 2017, Introducao ao Controle de Sistemas (Coursera), Instituto Tecnologico de Aeronautica, Delivered by Coursera.

Memoli, P., 2011, Virtual experiments, Project funded by HESTEM. http://www.edshare.soton.ac.uk/6589/1/preloader-diode.html.

Meng-jun, L., 2011, Application of NI myDAQ in Practical Education of Electronic Circuit Engineering. Journal of Hebei North University (Natural Science Edition).

Middleton,P.,2013, editor. Digital voices. ebook: http://melsig.shu.ac.uk/.

MIT, Massachusetts institute of technology - ilab. http://ilab.mit.edu/wiki.

Moon,I., S. Han, K. Choi, D. Kim, C. Jeon, S. Lee, and S. Woo, 2008, A remote laboratory for electric circuit using passive devices controlled. In Proc. International Conference on Engineering Education.

Murray,R.M.,2003, editor. Control in an Information Rich World: Report of the Panel on Future Directions in Control, Dynamics, and Systems. SIAM, http://dx.doi.org/10.1137/1.9780898718010.

Murray,R.M., S. Waydo, L. Cremean, and H. Mabuchi, 2004, A new approach to teaching feedback. IEEE Control Systems Magazine, 24(5):38-42.

Murray, R., 2013, Feedback Systems. www.cds.caltech.edu/ murray/wiki/Main_Page.

Nortcliffe, A. and A. Middleton, 2007, Audio Feedback for the iPod Generation. In International Conference on Engineering Education.

Panel Session, 2013, What does industry want?, IFAC symposium on Advances in Control Education.

Park,S.T., H. Lee, K. C. Yuk, and H. Lee, 2005, Web-based nuclear physics laboratory. In Recent Research Developments in Learning Technologies, pages 1165-1169.

Parson,V., P. Reddy, J. Wood, and C. Senior, 2009, Educating an iPod generation: undergraduate attitudes, experiences and understanding of vodcast and podcast use. Learning, Media, and Technology, 34(3):215-228.

Pasik-Duncan, B. and D. Duncan, 2002, Undergraduates' Partnership with K-12. In Proc. Amer. Control Conference, pages 1085-1088.

Pasik-Duncan, B. and M. Verleger, 2009, Education and Qualification for Control and Automation. In S. Y. Nof, editor, Springer Handbook of Automation, chapter 44a. Springer-Verlag Berlin Heidelberg.

Pasik-Duncan, B., 2004, Mathematics Education of Tomorrow. AWM Newsletter.

Pasik-Duncan,B., 2015, Teaching collaboration: Five KU teachers share their experiences. Teaching matters, published by CTE (University of Kansas), 18(2).

Pearce, D., 2008, Impact of Animated Visual Models in Enhancing Student Understanding of Complex Processes. Engineering Subject Centre teaching award.

Perez,J., S. Dormido, and L. Vlacic, 2011, Enhancing student learning: On-line interactive laboratory for modelling of real world control system applications. In IFAC world congress, pages $7268-7273$.

Porter, P., 2009, Using two and three dimensional graphical animations in powerpoint. In Blended learning conference.

Proceedings of 4th International Blended Learning Conference, University of Hertfordshire, 2009, ISBN 978-1-905313-66-2.

Y. Qiao, G. Liu, G. Zheng, and C. Luo, 2012, Design and realization of networked control experiments in a web-based laboratory. In Proc. UKACC.

Reck, R. and R.S. Sreenivas, 2015, Developing a New Affordable DC Motor Laboratory Kit for an Existing Undergraduate Controls Course (I). In $A C C$. 
RELOAD, Real labs operated at a distance. http://www.engsc.ac.uk/mini-projects/reload-reallabs-operated-at- distance, last checked 1/9/2010.

Rossiter, J.A., D. Giaouris, R. Mitchell, and P. McKenna, 2008 Typical control curricula and using software for teaching/assessment: a UK perspective. In IFAC world congress.

Rossiter,J.A., A. Nortcliffe, A. Griffin, and A. Middleton, 2009, Using student generated audio to enhance learning. Engineering Education Journal, 4(2):52-61.

Rossiter, J.A. and L. Gray, 2010, Supporting development of independent learning skills. Engineering Education.

Rossiter, J.A., 2011, Which technology can really enhance learning within engineering? International Journal of Elec. Eng. Educ., 48(3):231-244.

Rossiter, J.A., Y. Baradaranshokouhi, I. Lilley, and C. Bacon, 2011, Developing web accessible laboratories for introductory systems and control using student projects. In IFAC world congress.

Rossiter, J.A., 2012, Developing virtual laboratories for introductory control. In UKACC.

Rossiter, J.A., 2013, Using online lectures to support student learning of control engineering. In IFAC symposium on Advances in Control Education.

Rossiter, J.A., 2014, Lecture flipping for control engineers. In IFAC world congress.

Rossiter, J.A., S. Dormido, L. Vlacic, B. Ll. Jones, and R. M. Murray, 2014 Opportunities and good practice in control education: a survey. In IFAC world congress.

Rossiter, J.A., 2016, Lectures on youtube. www.youtube.com/channel/UCMBXZxdj6VqrynykO1dURw.

Saeedeh,Z.F., A. R. Guilherme, and M. Nina, 2015 GUPPIE, Underwater 3D Printed Robot a Game Changer in Control Design Education (I). In $A C C$.

San-Cristobal-Ruiz, E., P. Baley, M.A. Castro-Gil, K. DeLong, J. Hardison, and J. Harward, 2010, Integration view of web labs and learning management systems. In IEEE EDUCON.

Saunders, F.C. and I. Hutt, 2012, Richness, responsiveness and relationship: using rich media materials to enhance the teaching of core concepts. Engineering Education.

Schauer, F., F. Lustig, and M. Ozvoldova, 2006, Remote scientific experiments across internet: Photovoltaic cell characterization. In International Conference on Interactive Collaborative Learning.

Schauer, F., I. Kuritka, and F. Lustig, 2006, Creative Laboratory Experiments for Basic Physics using Computer Data Collection and Evaluation Exemplied on the Intelligent School Experimental System (ISES). In iNEER Special Volume: Innovations, pages 305-312.

Sivakumar,S.C., W. Robertson, M. Artimy, and N. Aslam, 2005, A web-based remote interactive laboratory for internetworking education. IEEE Transactions on Education, 48(4):586-598.

Stefanovic,M., V. Cvijetkovic, M. Matijevic, and V. Simic, 2011, A LabVIEW-Based Remote Laboratory Experiments for Control Eng. Educ. Computers Applications in Eng. Educ., 19:538549.

Taylor, B.P., B. Jones, and P. Eastwood, 2013, Development of low cost portable hardware platform for teaching control and systems theory. In IFAC symposium on Advances in Control Education.

TEAL: Technology-Enhanced Active Learning. web.mit.edu/edtech/casestudies/teal.html.

Tochan, E., 2017, Control System Analysis and Design (UNINETTUNO), International Telematic University, delivered by UNINETTUNO OpenupEd.

UK-SPEC, Engineering Council, 2016, http://www.engc.org.uk/ukspec.aspx.

Vargas,H., J. Sanchez, C. A. Jara, F. A. Candelas, F. Torres, and S. Dormido, 2011, A Network of Automatic Control Web-based Laboratories. IEEE Transactions on Learning Technologies, 4(3):197-208.

Walters, M., 2011, Work in progress - Tools and technology to implement a students personal laboratory. In Frontiers in Education Conference.

White, J. and Steinmeyer, J., 2017, Introduction to Control System Design - A First Look (edX), MIT Delivered on Coursera.

Williams, J. and M. Fardon, 2005, On-demand internet-transmitted lecture recordings: attempting to enhance and support the lecture experience. In $A L T-C$.

Wilson, D. and P. Maclaren, 2013, From Chalk Talk to Tablet Talk: Pedagogies for Control Engineering. In IFAC symposium on Advances in Control Education. 


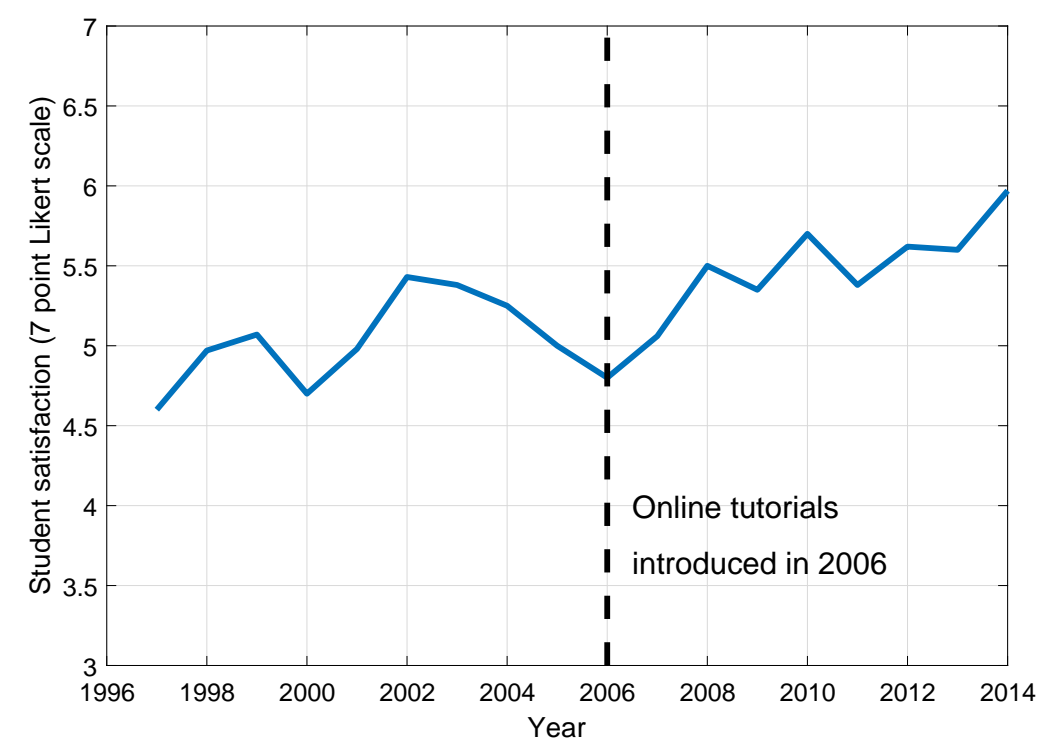

Figure 1. Historical values of student satisfaction with Animated Online Tutorials used with a Digital Control Systems Engineering course at Griffths University in Australia. This graph shows the mean value of numerical responses (on a 7 point Likert scale) to the question "Overall, I am satisfied with the quality of this course" over the years 1997 - 2014. A trend of increasing student satisfaction is observed since 2006, corresponds to when Animated Online Tutorials were introduced into the course.

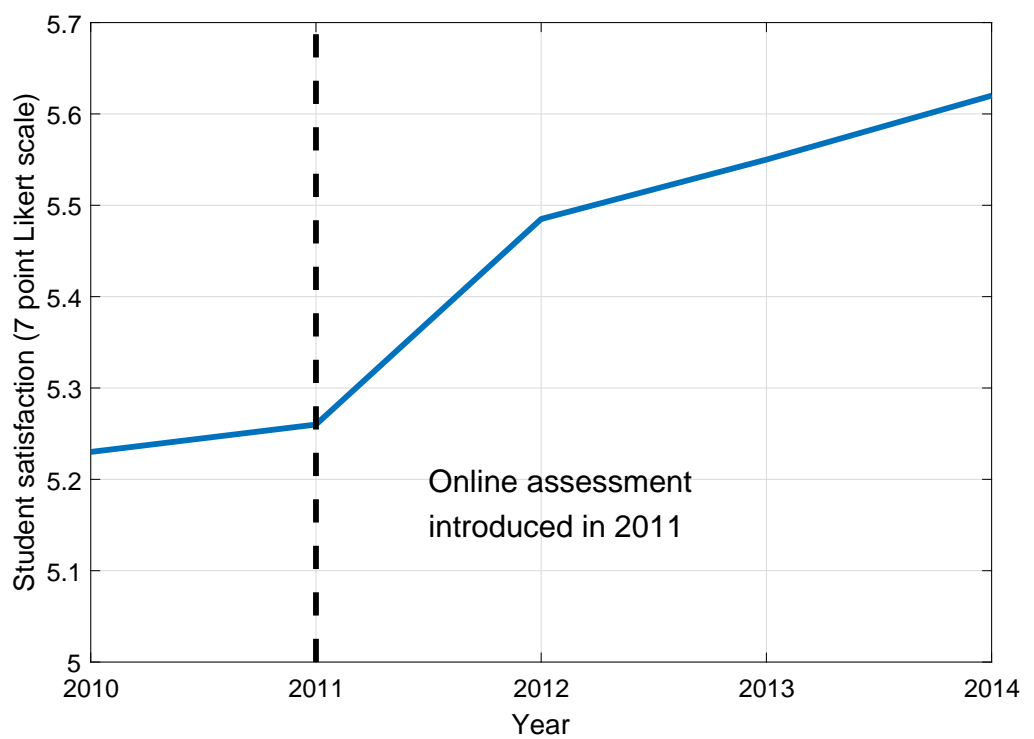

Figure 2. Historical values of student satisfaction with online assessment. The $2010-2014$ historical course satisfaction scores were calculated by averaging the mean score values obtained from three courses at Griffths University in Australia that now have significant online assessment components, where the online assessment was introduced in 2011.

Workshops and Special Sessions on Control Education. http://www.math.ku.edu/ksacg/bpdworkshops.html. 


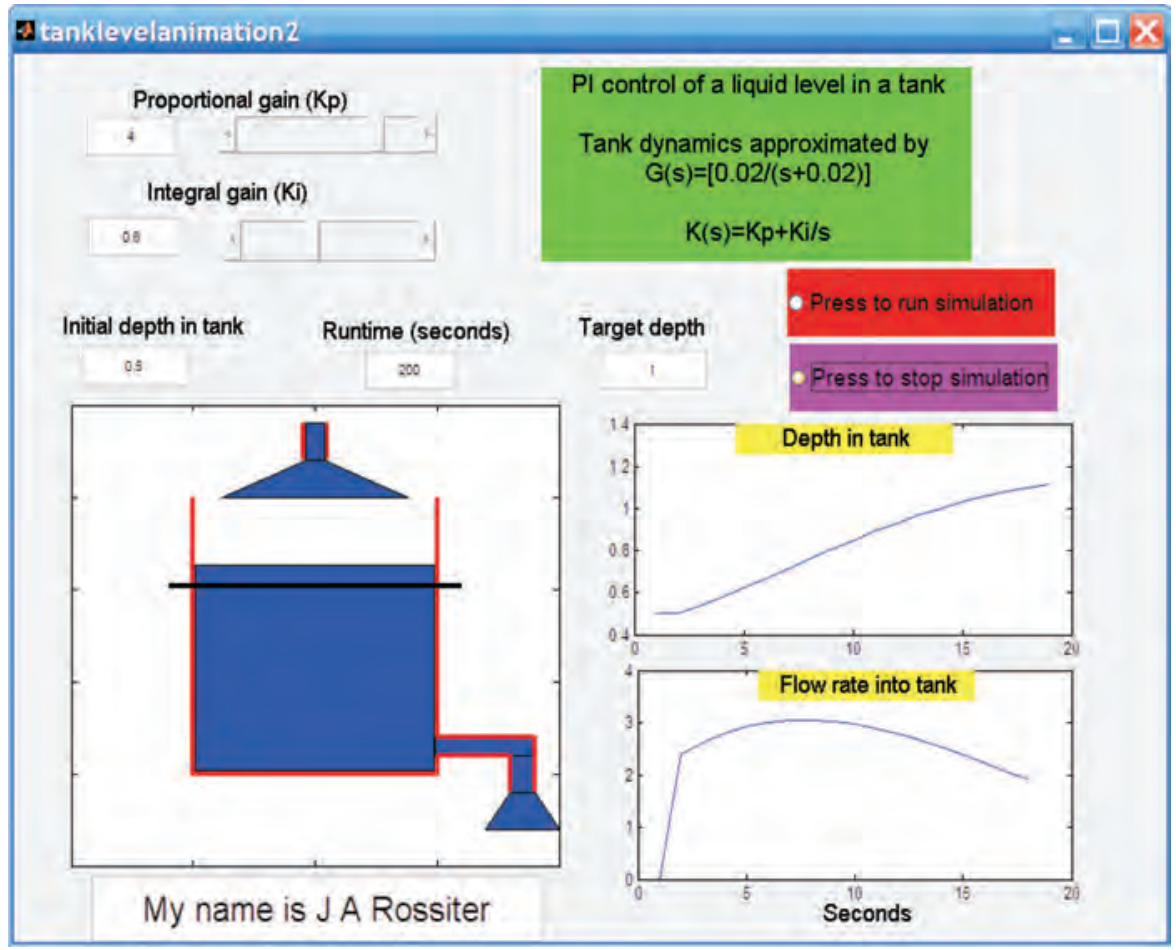

Figure 3. MATLAB GUI interface for simulation of tank level control. Simulations can be coded relatively quickly using MATLAB tools and readily provided to students for use on their own laptops. MATLAB tools allow teachers with minimal technological expertise to easily modify activities to suit the requirements of various lessons.

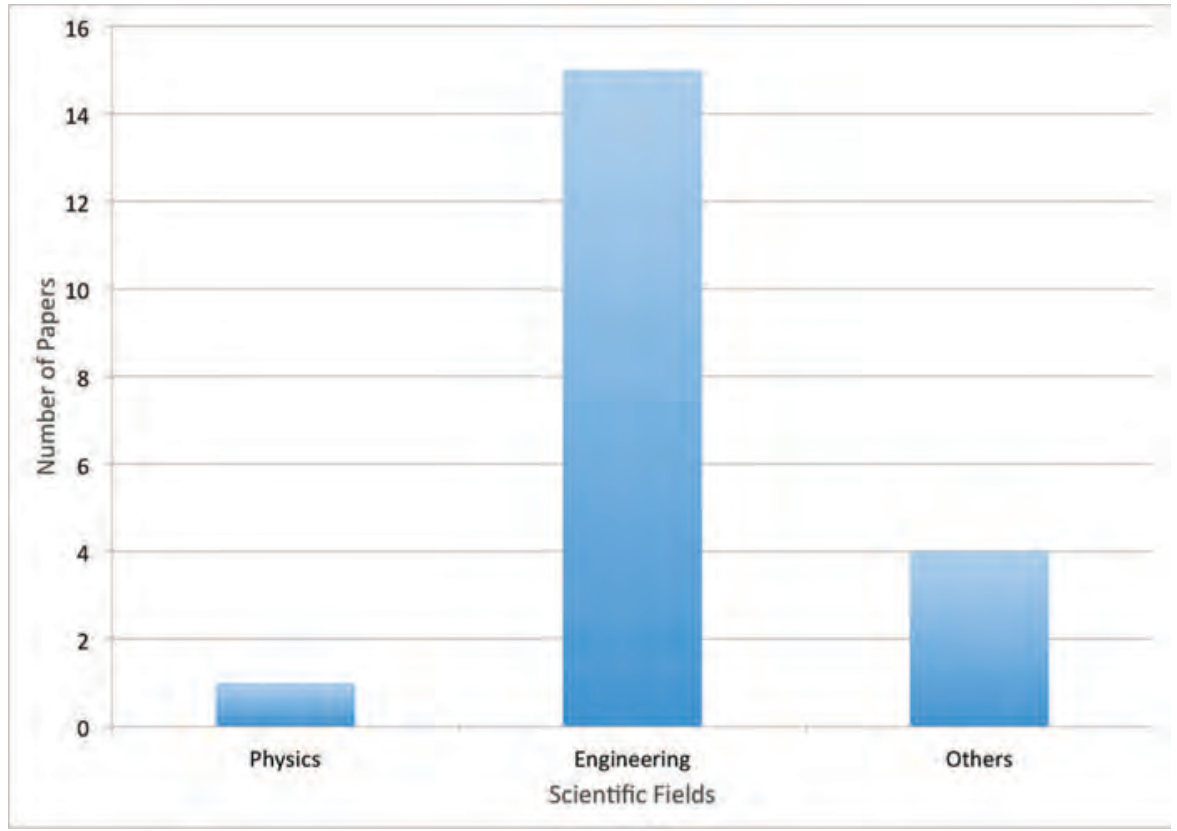

Figure 4. Distribution of scientific field considered in literature on RLs. Of 20 papers dedicated to RLs (from among the 60 papers on hands-on labs, VLs, and RLs discussed in (Ma and Nickerson 2006)), only 1 was about

Physics, whereas 15 were about Engineering (with a focus on Electrical Engineering).

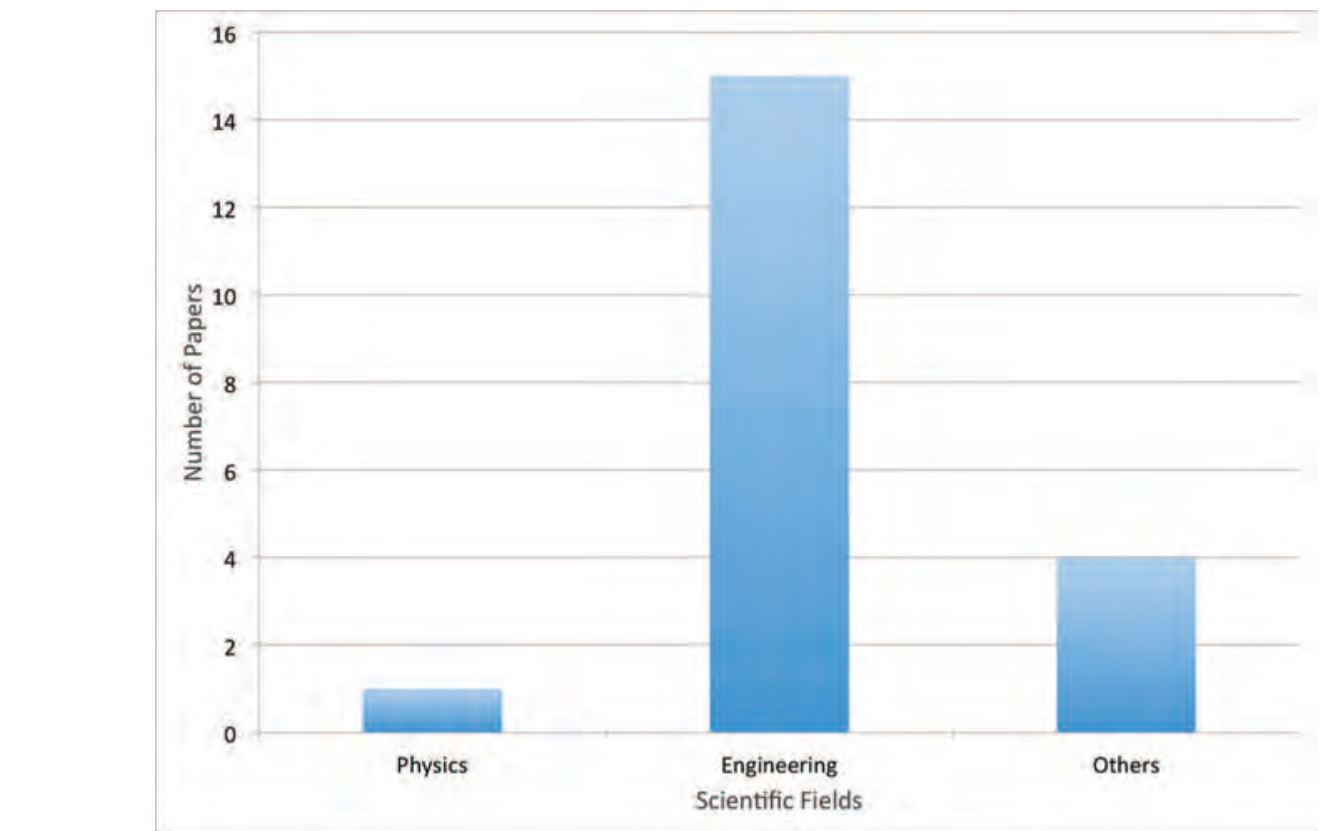




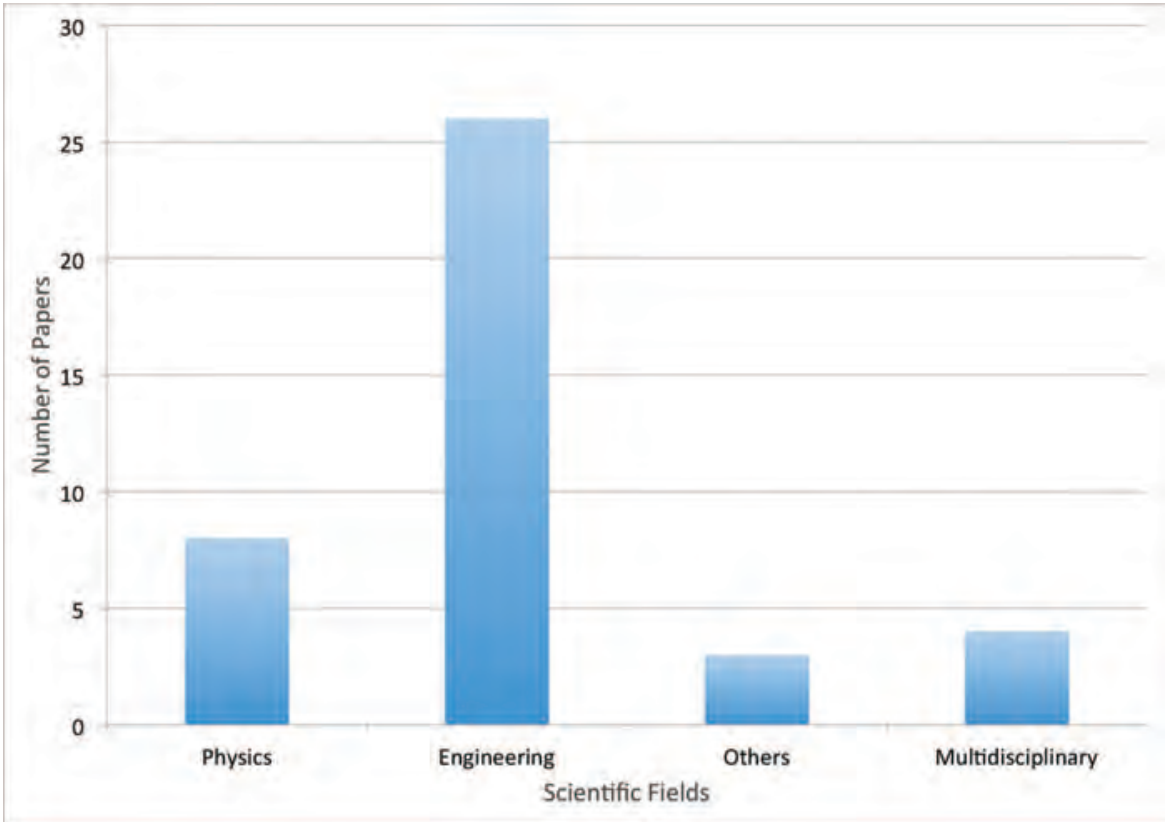

Figure 5. Distribution of scientific fields considered in literature on VRLs. Out of the 42 papers about hands-on labs, VLs, and RLs covered in (Gravier 2008), there were 26 dedicated to the Engineering discipline compared to only 8 related to Physics.

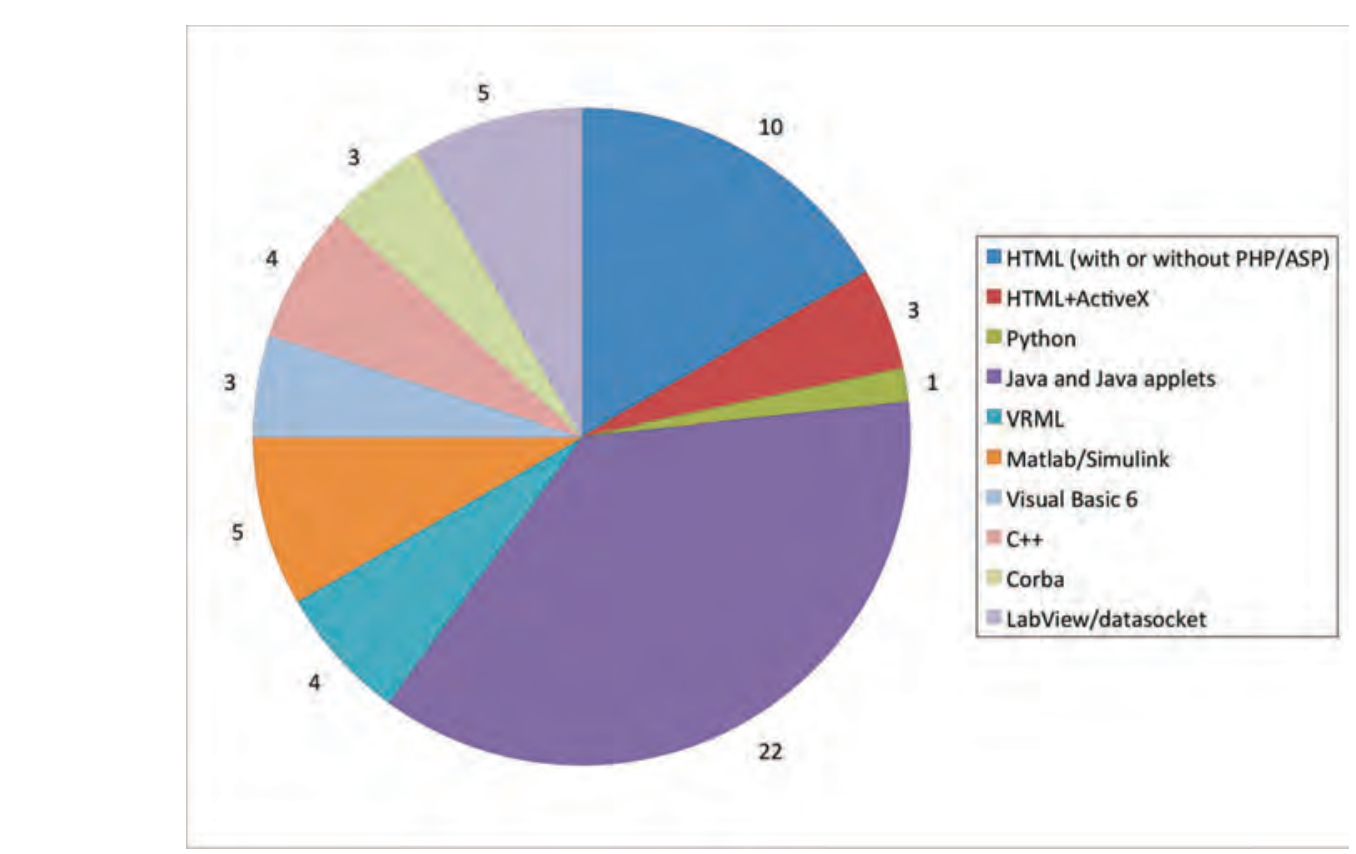

Figure 6. Distribution of technologies used by VRLs. As concluded in (Gravier 2008), Java is by far the most widely used medium for creating virtual and/or remote laboratories in the form of applets. 
